\title{
$-2$ \\ A PRODUÇÃO DO MATERIAL DIDÁTICO NO CONTEXTO COOPERATIVO E COLABORATIVO DA DISCIPLINA DE CÁLCULO DIFERENCIAL E INTEGRAL I, NA MODALIDADE DE EDUCAÇÃO A DISTÂNCIA, NA GRADUAÇÃO**
}

\author{
Elisa Netto Zanette ${ }^{* *}$ \\ Evânio Ramos Nicoleit** \\ Graziela Fátima Giacomazzo Nicoleit ${ }^{* * * * *}$
}

Resumo: Este artigo descreve o processo investigativo que permite planejar, organizar e produzir o material didático para uma disciplina da graduação na modalidade de Educação a Distância (EaD), no contexto do trabalho cooperativo e colaborativo. O material didático foi produzido no contexto de socialização em duas mídias: material impresso e publicado via Internet. Esta última por caracterizar-se como sendo uma mídia que reúne recursos favoráveis à cooperação e interação entre acadêmicos e professores. Aborda-se a utilização da modalidade não-presencial na disciplina de Cálculo Diferencial e Integral I e/ou equivalentes de alguns cursos de Graduação. Ao trabalhar-se a construção cooperativa e colaborativa do material didático, é possível melhorar de forma significativa a elaboração, pelos professores pesquisadores, dos conceitos matemáticos envolvidos. Isto pode contribuir para uma melhor formação do acadêmico na disciplina de forma consciente e criativa. A modalidade de educação a distância pode transformar-se num recurso mediador do processo educativo na disciplina.

Palavras-chave: educação a distância, material didático, colaboração cooperação, ambiente virtual.

Abstract: This article aims at describing the investigative process, which tries to understand the ways to plan, to organize and to produce teaching material for an academic discipline in the distance education modality in a collaborative and cooperative work context. The teaching material was produced in a socialization context in two media: printed material and material available via Internet, the latter for being characterized as a medium that has favorable resources for cooperation and interaction among teachers and students. The article presents the use of the distance modality for Differential and Integral Calculus $I$ and/or equivalent disciplines from some graduate courses. The collaborative and cooperative construction of teaching material helps researchers to improve, significantly, the elaboration of the mathematical concepts involved. That can contribute for a better academic formation in the discipline in a conscious and creative way. Distance education modality can become a mediator resource in the discipline educative process.

\footnotetext{
Artigo apresentado no XI Congresso Internacional de Educação a Distância - ABED, Salvador, 2004, alterado e atualizado para apresentação no VII Ciclo de Palestras sobre Novas Tecnologias na Educação - UFRGS - Porto Alegre, 2006.

"Matemática e Bióloga, Mestre em Educação, Universidade do Extremo Sul Catarinense UNESC, Professora e Coordenadora do SEAD Setor de Educação a Distância, enz@unesc.net, www.ead.unesc.net. Líder de Grupo de Pesquisa CNPq/Unesc - Educação a Distância na Graduação.

*** Engenheiro Eletricista, M.Eng. Engenharia Elétrica.-Ufsc, Universidade do Extremo Sul Catarinense - UNESC, Professor, ern@unesc.net, Vice-Lider do Grupo Pesquisa CNPq/Unesc - Educação a Distância na Graduação, Líder de Grupo de Pesquisa CNPq/Unesc - Informática Médica e Telemedicina www.kiron.unesc.net.

Pedagoga, Especialista em Psicologia Escolar, Universidade do Extremo Sul Catarinense UNESC, Professora, gfg@unesc.net, www.ead.unesc.net. Mestranda em Educação (UFRGS). Integrante de Grupo de Pesquisa CNPq/Unesc - Educação a Distância na Graduação.

V. $4 \mathrm{~N}^{\mathrm{o}}$ 1, Julho, 2006
} 
Keywords: Distance education; teaching material; collaboration; cooperation; virtuaenvironment.

\section{Introdução}

As possibilidades que se apresentam com o uso das Tecnologias de Informação e Comunicação (TIC's) têm provocado um impacto em diferentes dimensões, com resultados, compreensões e incorporações distintas. Este é o recente desafio para os educadores em sua prática educativa, os quais desempenham papel importante no processo de implementação desses recursos.

O uso das TIC's, aplicadas na educação, promove a interação virtual síncrona e assíncrona envolvendo educandos, professores e instituição. Mesmo dispersos geograficamente podem integrar-se em grupos de estudos, numa grande rede de comunicação, via Internet.

O reconhecimento da EaD no Brasil como uma modalidade de educação, impõe aos educadores desafios a serem superados num curto espaço de tempo. Concebida como uma forma alternativa de ensinar e apreender pode representar uma efetiva democratização da educação. Nessa concepção pode oportunizar, além do conhecimento socializado, a superação de alguns problemas no processo ensino aprendizagem, respeitando os ritmos de aprendizagem dos estudantes o que nem sempre é possível na modalidade presencial.

No âmbito da Educação Universitária, as áreas das ciências exatas, historicamente, têm apresentado dificuldades no processo ensino aprendizagem. São evidentes os desníveis dos acadêmicos em sua formação, incluindo as diferentes exigências nos programas curriculares dos cursos. A área da matemática exemplifica estas situações reais, encontradas por um grupo de professores pesquisadores que buscam investigar este contexto, para contribuir na melhoria do processo ensinoaprendizagem na disciplina de Cálculo Diferencial e Integral I. Partindo deste diagnóstico, o grupo de professores viabilizou a correspondente disciplina na modalidade de EaD. Este trabalho envolve a análise do processo de construção colaborativa e cooperativa do material didático da disciplina de Cálculo Diferencial e Integral I, na modalidade de EaD. Esta análise parte do desenvolvimento do material didático no enfoque de representações semióticas dos objetos matemáticos, contextualizados historicamente e propõe atividades de intervenção pedagógica na graduação visando a superação das dificuldades na apropriação dos conhecimentos científicos matemáticos. O uso das TIC's em Educação Matemática, possibilita novas práticas pedagógicas. Permite, pelo uso de seus recursos tecnológicos, pesquisar, fazer antecipações e simulações, confirmar idéias prévias, experimentar, criar soluções e construir novas formas de representação mental.

\section{Pressupostos Teóricos do Processo Ensino Aprendizagem}

A aprendizagem humana é um fenômeno em constante mudança.Na perspectiva da educação formal ocupa o lugar em relações educativas, que se definem como uma dinâmica entre os sujeitos envolvidos, tendo como objeto de estudo um determinado corpo de conhecimentos.

Com a contribuição das tecnologias no aumento das informações disponíveis, é crescente uma revolução no pensamento acerca do conhecimento (Levy, 1993). Isso poderá contribuir para uma Educação Aberta, Continuada, Presencial e a Distância. A interaçao entre o sujeito e o objeto e as mediações envolvidas no processo são de suma importância. Neste trabalho são abordadas estratégias pedagógicas para a educação adequadas ao contexto da modalidade a distância. Isso implica no 
conhecimento acerca das teorias pedagógicas construídas historicamente, que fundamentam os processos de ensino-aprendizagem na educação presencial e nãopresencial e dos recursos tecnológicos disponíveis (Preti, 2000).

Nesse contexto inserem-se as tecnologias na educação, como ferramentas de apoio e que podem transformar o aprender, num processo maisconstrutivo. As TIC's possibilitam uma maior interação, e podem ser usadas como instrumento de comunicação, de pesquisa e de produção de conhecimento. Isto implica: saber acessar o conhecimento, isto é, localizar e selecionar o que é relevante e; dar sentido ao conhecimento e/ou integrar a conhecimentos anteriores.

No enfoque de processo ensino aprendizagem, os conceitos são produzidos e apropriados pelo homem, atendendo a interesses, necessidades sociais, culturais e políticas das diferentes épocas (Vygotsky, 1994). Nestes conceitos insere-se a relação da Matemática com as tecnologias e com a práxis do educador. A intervenção do educador no processo pedagógico pode acontecer em momentos distintos, seja na construção de um recurso pedagógico, na aplicabilidade ou na análise dos seus resultados.

Este trabalho atua no processo ensino aprendizagem de Cálculo Diferencial e Integral I no contexto Universitário através da $\mathrm{EaD}$, optando pela concepção histórico-cultural de aprendizagem. Contempla-se assim, os pressupostos teóricos do sócio-interacionismo e do construtivismo. A concepção sócio-interacionista, preocupa-se em compreender como se constituem as interações sociais. Nessa perspectiva o conhecimento está nas relações sociais, enfatizando a relevância dos processos interacionais, entre os sujeitos e o objeto. No construtivismo o indivíduo é agente ativo na construção dos conhecimentos, ele age sobre o objeto transformando-o e desta forma transforma-se a si mesmo. Isto possibilita a construção de significados e a representação da realidade de acordo com suas experiências e vivências em diferentes contextos.

\section{Planejamento e Organização do Material Didático na Disciplina de Cálculo Diferencial e Integral I para EaD}

A interação no grupo deve assumir a condição de uma investigação e, a cada reflexão sobre a ação realizada, buscam-se parâmetros para a reformulação das próximas ações. Considera-se que o fazer educativo é um processo contínuo de açãoreflexão-ação.

Concebe-se o professor como um investigador comprometido com o conhecimento das técnicas pedagógicas, com domínio de conteúdos, com um somatório de experiências vivenciadas e, aberto para a socialização desses saberes com um grupo multidisciplinar.

O planejamento e a organização do material didático neste processo encontra nesses pressupostos subsídios para sua elaboração. Trabalhar coletivamente está associado a socializar conhecimentos e práticas, pois implica na generalização da produção individual para a produção em grupo. É o trabalho no conceito de colaboração e cooperação que possibilita esta ação (Okada, 2003).

A organização do trabalho nesta ótica apresenta muitas vantagens. Dentre elas: o grupo pode produzir melhores resultados do que atuando individualmente; socializar conhecimentos e práticas; cooperação na resolução de tarefas; diferentes interpretações e pontos de vista, possibilitando uma visão mais ampla do tema em debate.

Entretanto, trabalhar em grupo também gera problemas como a difusão de responsabilidades, a competição, a falta de empenho, o controle de acessos e a 
sobrecarga de comunicação. Esses problemas exigem uma gerência eficiente que coordene o grupo de modo que todos cooperem (Gerosa et al, 2001).

\section{Produção do Material Didático no Contexto de Cooperação e Colaboração}

A metodologia de produção e edição do material tem contemplado momentos de colaboração e momentos de cooperação. Inicialmente, predomina o processo de produção cooperativa. Dessa forma foram desenvolvidos os materiais didáticos referentes às Unidades de Estudo 1 e 2 que tratam sobre: Intervalos Numéricos e Funções Reais de Variáveis Reais e os textos complementares dessas unidades.

Nesse processo de produção, o planejamento, a elaboração e a edição eram compartilhados. Foram designadas funções para cada membro integrante do grupo e cronograma. A primeira tarefa, desenvolvida por cada integrante do grupo de professores autores, referia-se à coleta dos materiais sobre os temas em estudo, a partir de uma revisão bibliográfica detalhada. A partir de encontros de estudo semanais os resultados eram socializados. Nesses encontros define-se o processo de planejamento da estrutura do conteúdo referente ao tema em estudo.

$\mathrm{Na}$ produção colaborativa a redação preliminar do texto a partir dos materiais selecionados é atribuída ao professor autor. A partir da edição preliminar do texto, os arquivos são compartilhados com os professores autores. Nesta etapa os arquivos são transferidos via correio eletrônico. Cada professor faz a sua análise e a inserção de contribuições diretamente no texto. Os professores autores devem ter familiaridade com as ferramentas de edição de textos. Deve haver um registro histórico da evolução textual. Esse registro pode ser feito utilizando-se diferentes meios: ambientes virtuais de aprendizagem, CD-ROM, repositórios eletrônicos, entre outros.

Esta atividade organiza-se de modo que o arquivo é transferido do professor A para o B, este para o C e assim sucessivamente. Dentro de um período, o texto é avaliado e alterado, quando necessário, pelos professores autores. Nesse processo de alteração, deve ser realizado um controle de alterações para permitir ao professor B, perceber as alterações feitas pelo professor A, como ilustrado na Figura 1. Assim, evidenciam-se as contribuições, evitando que um colega exclua uma contribuição recém inserida. As alterações não-aceitas integralmente são debatidas nos encontros.

\begin{tabular}{|c|c|}
\hline $\begin{array}{l}\text { MUDANCA DE BASE } \\
\text { - Até o momento, em todas as propriedades utilizadas consideramos o fato de } \\
\text { os logaritmos estarem sempre na mesma base. } \\
\text { - Suponha agora que apareçam bases diferentes e que precisemos reduzir os } \\
\text { logaritmos de bases diferentes para uma base conviniente. } \\
\text { - Esta operação chama-se mudanca de base. }\end{array}$ & $\begin{array}{l}\text { MUDANCA DE BASE } \\
\text { - Observe que: Todas as atividades envolvendo o conceito de logaritmo, Aaté o } \\
\text { momento, referiam-se a logaritmos com a mesma base. Portanto, em todas as } \\
\text { propriedades utilizadas, consideramos o fato de os logaritmos estarem sempre } \\
\text { na mesma base. E, se os logaritmos tem bases diferentes? } \\
\text {-Neste caso, devemos Suponha agora que apareçam bases diferentes e que } \\
\text { precisemos reduzir os logaritmos de bases diferentes para uma base } \\
\text { conveiniente. } \\
\text { - Esta operação chama-se mudanca de base. }\end{array}$ \\
\hline
\end{tabular}

Figura 1 - Produção de texto sem e/ou com controle de alterações.

Fonte: Dados da Pesquisa.

Esse processo mostra-se simples e eficiente, exigindo uma utilização dos recursos tecnológicos disponíveis. Os textos passam por esse processo de transferência constante dos arquivos entre os professores autores, até que os mesmos sejam considerados adequados. A evolução da escrita no contexto de linguagem matemática quanto às características de universalidade, objetividade, precisão é evidente. No processo de produção cooperativa, o trabalho é realizado com a intervenção direta entre 
duas ou mais pessoas no mesmo texto. Este processo caracteriza-se por um refinamento do material produzido, melhora qualitativa com maior requerimento de tempo necessário. No processo de produção colaborativa, as produções individuais são agregadas às demais produções, mostrando-se mais ágil e simplificado.

Para a produção das Unidades de Estudo 3 e 4 - Funções e Limites optou-se pelo processo de colaboração pela agilidade na produção, comparando-o com as primeiras produções do grupo no contexto eminentemente cooperativo. Neste caso, cada professor fica responsável por um tópico da Unidade. Após a edição o material é socializado e revisado pelos colegas.

Os materiais produzidos na perspectiva colaborativa e/ou cooperativa, necessitam de uma adequação de linguagem para $\mathrm{EaD}$, de uma revisão gramatical e posterior tratamento de editoração, antes de serem publicados nas mídias escolhidas.

\section{Estrutura e Avaliação do Material}

O processo de avaliação do material didático pelos acadêmicos ocorre a partir das versões impressa e online, disponibilizada no Ambiente Virtual de Aprendizagem (AVA), conforme Figura 2.

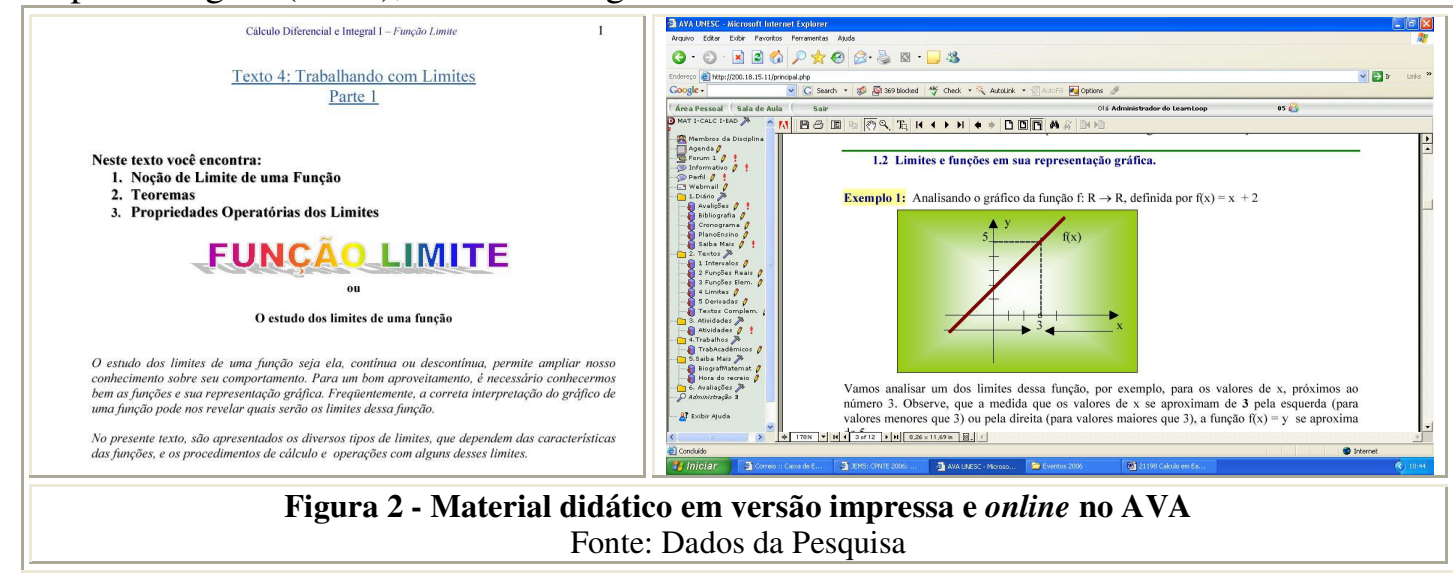

No AVA, os acadêmicos têm acesso somente à versão final publicada em pasta específica. A avaliação realizada pelos acadêmicos pode ser publicada em um fórum, criado especificamente para esse fim. A partir das considerações, os textos devem ser revistos e, se necessário, sofrer as devidas alterações.

Optou-se por uma estrutura baseada nos referenciais teóricos adotados na produção de material didático, objetivando manter as características de cada linguagem, propiciar a visualização e a distinção entre objeto de estudo e sua representação.

No contexto histórico dos conceitos matemáticos, são produzidas estratégias para facilitar a construção do conhecimento pelos acadêmicos a partir do entendimento da evolução do conhecimento matemático (Fleminng, 2003). Este contexto pode auxiliar o professor no processo de ensinar: pelo significado e compreensão; pelo reconhecimento da dificuldade inerente dos conceitos matemáticos; e por propiciar novas idéias. Como exemplo, na Figura 3, faz-se um resgate histórico sobre a trigonometria. 


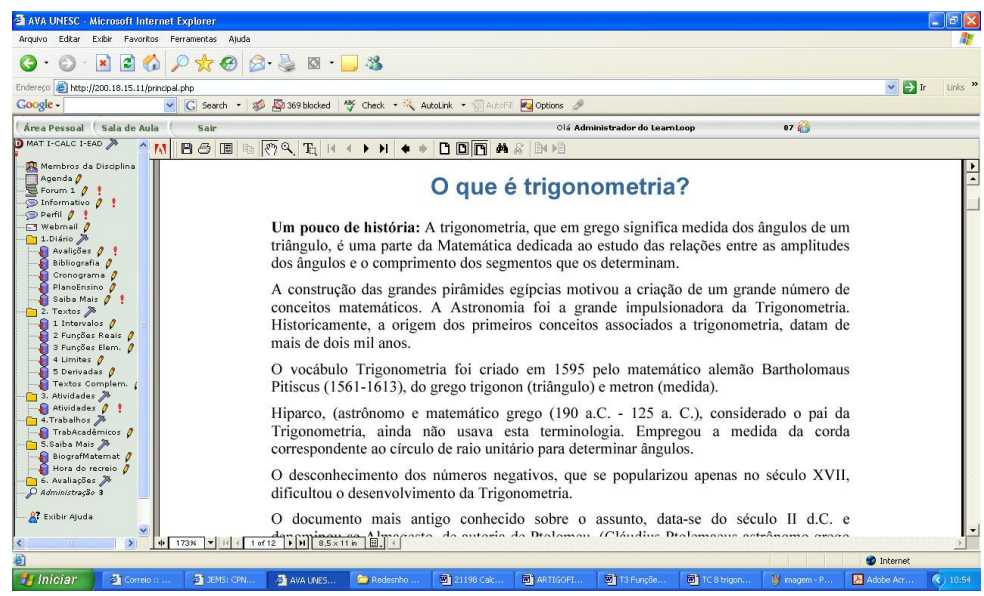

Figura 3: $O$ contexto histórico da Matemática

Fonte: Dados da Pesquisa - Sead/Unesc

Quanto ao contexto cotidiano, busca-se fazer uma associação entre o significado do conteúdo abordado e a prática habitual do acadêmico. Neste cotidiano, vai se constituindo os modos de pensar, agir, sentir, conhecer e perceber o mundo. $\mathrm{O}$ uso de exemplos de situações do cotidiano propicia o aprendizado, pois dão significado aos conteúdos abordados. Para propiciar a integração de diversas áreas da Matemática, se apresenta as representações temáticas semióticas de diferentes registros, visando ampliar a compreensão e a apropriação do conceito. Na Figura 4, apresenta-se um recorte da apresentação de um tema integrando áreas da Matemática (geometria e álgebra). Neste caso o acadêmico tem acesso a registros diversos de uma mesma representação semiótica visando ampliar a compreensão e a apropriação do conceito.

A utilização de aplicativos informáticos deve ser adotada na apresentação visual de figuras que representam graficamente as funções e os conceitos abordados, visando propor a reflexão a partir da comparação entre os objetos. A Figura 5, mostra a análise comparativa da variação da função a partir do coeficiente angular, exemplificando este uso.

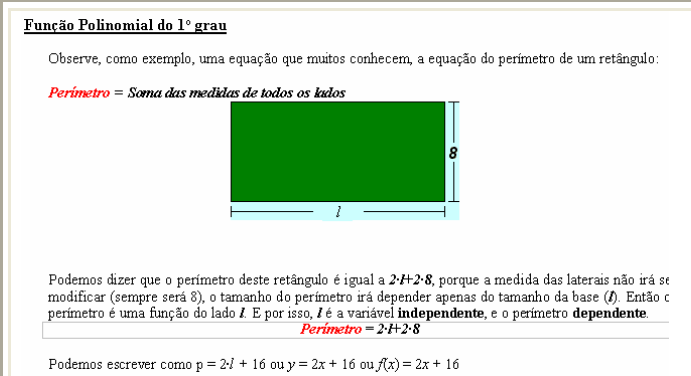

Figura 4 - Registros diversos de uma mesma representação semiótica Fonte: Dados da Pesquisa

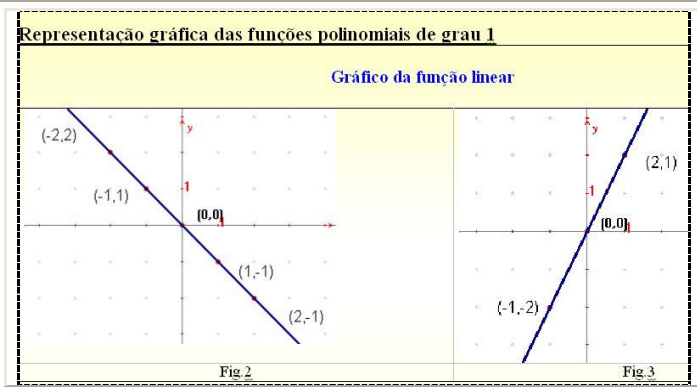

Figura 5 - A representação gráfica das funções lineares no software Cabri Géomètre II. Fonte: Dados da Pesquisa.

Os primeiros textos produzidos foram submetidos à apreciação dos acadêmicos nas aulas presenciais dos professores autores, durante o $1^{\circ}$ semestre de 2003. A análise dessa avaliação apontou equívocos de digitação, até a necessidade de ampliar conteúdos que haviam sido abordados superficialmente pelos professores na produção dos textos. Esse processo propicia aos professores autores, novas reflexões sobre a forma de produzir o material. Deve ser considerado que o acadêmico, ao interagir com o material, não tem ao seu lado um professor e/ou colega mediando o processo nesta modalidade. Estes questionamentos continuam permeando a produção e avaliação dos resultados dos demais textos. Durante o processo de execução da proposta 
pedagógica experimental, em forma de pilotagem, as correções são imediatamente realizadas.

\section{Primeiros Resultados}

No segundo semestre de 2003 ocorreu a primeira edição da disciplina de Cálculo Diferencial e Integral I, na modalidade de educação a distância, na graduação. Treze acadêmicos de diferentes cursos que já haviam cursado a Disciplina foram os alunos envolvidos. Destes doze obtiveram aprovação.

No primeiro semestre de 2004 ocorreu a segunda edição da disciplina novamente na modalidade de EaD. Nesta edição, doze acadêmicos de diferentes cursos que já haviam cursado a disciplina integraram o público de alunos. Oito obtiveram aprovação. No segundo semestre de 2004 ocorreu a terceira edição com 16 acadêmicos de diferentes cursos que já haviam cursado a disciplina. Oito obtiveram aprovação e sete desistiram. Nestas edições ocorreu a participação de um bolsista de Iniciação Científica para auxiliar na observação direta da prática docente e execução de registros bem como na monitoria e acompanhamento na realização das atividades - quando solicitado.

A partir das análises das dificuldades apresentadas, novas orientações têm sido discutidas pelo grupo no sentido de aprimorar o processo. Levando-se em consideração a dificuldade do conteúdo envolvido, faz-se necessário um suporte de orientação e acompanhamento por parte do grupo de professores Desta forma, o grupc deve desenvolver práticas e recursos pedagógicos inovadores para a ação docente.

Nesta perspectiva novas estruturas de materiais vêm sendo desenvolvidos em hipermídia e objetos de aprendizagem.

\section{Considerações Finais}

Neste artigo foi descrito o processo de construção de um projeto cooperativo e colaborativo na elaboração do material didático na disciplina de Cálculo Diferencial e Integral I na graduação. Priorizou-se o processo de construção multidisciplinar. Nesse enfoque, cada participante traz informações relevantes para o grupo, contribuindo assim, para uma melhor interação social entre seus pares e um crescimento individual e coletivo. Nesse processo, são importantes as habilidades de troca de conhecimento entre os sujeitos, comprometimento, negociação e entendimento no compartilhamento do problema, além da ajuda mútua em resolvê-lo. Todos são aprendizes e podem contribuir um com o outro.

O trabalho cooperativo e colaborativo, nesse contexto, representa a construção coletiva do conhecimento num processo de interação e interatividade contínuo. A interação e as trocas não se caracterizam apenas pelos aspectos cognitivos, mas também pelos aspectos sociais.. A relação entre os professores participantes e seus conhecimentos prévios a cerca dos conteúdos influencia de maneira significativa na interação e isso reflete no contexto de trabalho. Evidenciou-se nesta experiência, que existe um tempo para os envolvimentos entre os professores, para emergir as intenções e as ações coletivas. A partir disso, o processo interativo avança, os participantes permitem as intervenções e a aceitação da contribuição do outro sobre a sua produção.

A apropriação dos recursos tecnológicos, as concepções sobre as formas e o conteúdo didático-pedagógico ocorrem em momentos distintos entre os professores envolvidos. Portanto, é preciso compreender o tempo e o espaço de cada um, para que, a partir da rede de significados coletiva, cada um desenvolva seu potencial, reflita sobre sua prática e implemente mudanças que possam contribuir com o trabalho. 
Estar envolvido numa rede de colaboração auxilia e amplia os significados tanto no contexto de conhecimento quanto no contexto de comunicação. $\mathrm{O}$ planejamento e a organização do material didático proposto para a disciplina Cálculo Diferencial e Integral I permitiu aos professores acompanhar, analisar e avaliar todo o processo de produção do material didático e isso refletiu positivamente na prática docente na modalidade presencial.

Esta experiência abre novas possibilidades para outras propostas, que se inserem nas abordagens de construção colaborativa e/ou cooperativa e nas constituições de grupos multidisciplinares. Entretanto, algumas ações podem ser implementadas no desenvolvimento de projetos similares a partir das sugestões do grupo envolvido: o uso de ferramentas colaborativas online para a produção textual coletiva que agregue recursos de representações semióticas, usuais na Matemática, como símbolos, figuras, representações gráficas, tabelas, etc; professores autores e tutores com disponibilização de tempo e interesse para participar desses projetos; edição do material textual por técnicos a partir das produções dos professores autores; espaços físicos e tecnológicos adequados para os estudos em grupo; ampliação dos debates entre os envolvidos sobre a modalidade de EaD incluindo a produção de material didático; ações que possibilitem a todos os integrantes usar os recursos de comunicação e informação disponíveis.

A proposta apresentada, desenvolvida e organizada no contexto cooperativo e colaborativo, não esgota o tema. O projeto, em seu estágio de execução como experiência piloto na disciplina, possibilitou ganhos significativos ao estudante na sua formação acadêmica. As primeiras etapas de desenvolvimento do mesmo caracterizam-se por avanços no contexto de detectar dificuldades, buscar e propor ações que refletem na melhoria da aprendizagem dos acadêmicos. A implantação e validação da mesma pelo grupo de pesquisadores, na modalidade de EaD e no contexto de Educação Matemática, poderá ampliar esta análise e permitir o aperfeiçoamento da mesma na busca de proposições que viabilizem com qualidade essa modalidade de educação.

Neste trabalho constatou-se que é possível construir de forma cooperativa e colaborativa o material didático de uma disciplina da graduação na modalidade de EaD., O processo de construção do material didático da disciplina de Cálculo Diferencial e Integral I, na modalidade de $\mathrm{EaD}$, contribuiu para o enriquecimento da mesma na graduação, como afirmam os professores e acadêmicos envolvidos.

\section{Referências Bibliográficas}

AZEVEDO, Wilson. A educação online sem ilusões. Disponível em: <http://www.aquifolium.com.br/educacional/gazetarj/> . Acesso em: 03 mar 2001. FLEMMING, D.M.; LUZ, E.F.; COELHO, C. Desenvolvimento de material didático para educação a distância no contexto da educação matemática. Florianópolis : UNISUL, 2003, Disponível em

$<$ http://www.abed.org.br/publique/cgi/cgilua.exe/sys/start.htm?UserActiveTemplate=4a bed\&infoid=171\&sid=105> Associação Brasileira de Educação a Distância. Acesso em: 31 mar. 2003

GEROSA, M.A.; FUKS, H.L.; LUCENA, C.J.P. Tecnologias de informação aplicadas à educação: construindo uma rede de aprendizagem usando o ambiente AulaNet. In: UFRGS. Informática na Educação: Teoria \& Prática, Porto Alegre, v.4, n.2, p. 6373, dez.2001. LÉVY, Pierre. As tecnologias da inteligência: o futuro do pensamento na era da informática. Tradução de Carlos Irineu da Costa. São Paulo: Editora 34, 1993. 
OKADA, Alexandra Lilavati Pereira. Desafios para EaD: Como fazer emergir a colaboração e a cooperação em ambientes virtuais de aprendizagem. In: SILVA, Marco (Org.) Educação online: Teorias, práticas, legislação e formação corporativa. São Paulo: Loyola, 2003. p.273-291.

PRETI, Oreste (Org.). Educação a Distância: construindo significados. Brasília: Plano, 2000.

VIGOTSKY, L. S. A formação social da mente. São Paulo: Martins Fontes. 1994 